\title{
Forum
}

\section{The Mental Health Acts and people with severe learning disability}

\author{
David H. James, Consultant Psychiatrist, Cornwall and Isles of Scilly Mental Handicap \\ NHS Trust, Truro TR1 1NR
}

As a consultant in the psychiatry of learning disability for the past 18 years, I had assumed that the Mental Health Acts referred to those patients who have some understanding of the concept of treatment and who are able to clearly express an objection to any proposed management. Those who could not express an objection because of severe handicap ("non-volitional patients"), I treated as informal patients. This view was supported by a representative of the Medical Protection Society, with whom I had discussions soon after I became a consultant. It agrees with the assumption that is widely held that for informal admission to occur, a person need not express positive willingness to be admitted to hospital, that it is sufficient that he is not unwilling to be treated in hospital (Gostin, 1983).

I believed that I had a "duty to care" for those patients which included the use of seclusion, restraint or being treated in locked areas if it was in their best interests or for the protection of others and it was prudent for such treatment or management plans to be generally agreed and agreeable to all those concerned with the patient.

This view was recently challenged during a visit of the Mental Health Act Commissioners who suggested that those people with mental impairment who fulfilled the criteria of the Act and who needed admission to a secure environment, seclusion or restraint, should be subject to the Act.

This view of the Act as a safeguard for vulnerable people who are unable to give valid consent for psychiatric treatment is expressed by Professor Elaine Murphy, Vice Chairman of the Mental Health Act Commission:

"The Mental Health Act of 1983 ... emerged from a common concern that individuals who are ill or handicapped in ways that render them incapable of making autonomous decisions are vulnerable. They need special protection to ensure that their treatment and care is warranted, does not fall below a certain standard of practice and that they are protected from unnecessary ill treatment" (Murphy, 1990).
I felt it was important to find out the views of my colleagues about the use of the Mental Health Act for patients with severe learning disability and whether the occurrence of behaviour requiring restraint or seclusion would warrant detention under the Act. The aim is to promote consistency in the use of the Act for this client group as part of our medical audit.

\section{The questionnaire}

I circulated a questionnaire to the 15 consultants in mental handicap psychiatry in the South West Region who see adult patients. All questionnaires were returned.

The questionnaire outlined ten hypothetical situations involving the management of inpatients with severe learning disability using seclusion, restraint, locked doors or medication. Consultants were asked whether they would use the Mental Health Act in each situation.

The questionnaire showed a spread of opinion about the use of the Act. Two consultants would only use the Act in one of the ten hypothetical situations, while one consultant would use the Act in nine of the ten situations. The majority of consultants fell between these two extremes and would use the Act only in certain of the situations described in the questionnaire.

Dividing the consultants into two groups, those who were more likely to use the Act (six consultants) and those less likely to use the Act (nine consultants), those less likely to use the Act had more in-patient beds and not surprisingly fewer detained patients. There were no differences between the two groups in the length of service as a consultant or in the frequency with which they were asked to assess patients for detention under the Act.

\section{Seclusion}

Consultant opinion about using the Act depended on the frequency that seclusion was being used. The majority of consultants (13) would use the Act if 
seclusion was used at least once a week and ten consultants if seclusion was used at least once a month. But if seclusion was used less frequently than once a month only a minority of consultants (three) would detain the patient under the Act.

\section{Restraint}

For patients with a severe learning disability requiring physical restraint by staff because of serious aggression, the use of the Act again depended on the frequency that restraint was required. If the restraint was required at least once a week, six consultants would use the Act, at least once a month, three consultants and less than once a month, one consultant.

For patients with a severe learning disability requiring physical restraint (splinting) because of self-injurious behaviour for 'much of the time' only two consultants would use the Act.

\section{Locked ward areas}

The use of the Act depended on the patients' willingness to return to hospital. No consultant would use the Act to detain patients who persistently try to leave the ward, who have little awareness of traffic or other dangers, but who make no resistance to being returned to the ward.

If, however, the patient does resist return, nine consultants would use the Act.

\section{Medication}

The majority of consultants (ten) would use the Act if a patient with a severe learning disability persistently refuses to take psychotropic medication prescribed for severe aggression.

\section{General Comments}

A number of general comments were made by consultants returning the questionnaire:

(a) that the Mental Health Act 1983 does not specifically address the needs of people with severe learning disability and is difficult to apply in practice to this client group (b) the lack of legislation to deal with adult clients in the community who do not fulfil the criteria for mental impairment, but who require to be removed from their present situation in their own interest or the interests of others

(c) the confusion and overlap that exists between the definitions of psychopathy and mental impairment

(d) that misplaced 'liberalism' can lead to a reluctance to use the Act which robs a vulnerable group of proper legal safeguards

(e) that every effort should be made to discover the intentions and wishes of the patient (using Makaton or other signing systems if appropriate).

\section{Conclusion}

The survey showed that while most consultants in learning disability think that the 1983 Mental Health Act applies to people who are unable to give or withhold consent because of severe learning disability, there are difficulties and differences in using the Act for this client group.

These results have been discussed by the South West Group of Consultants in Learning Disability. The Group wishes to promote further discussion of the difficulties surrounding the use of the Mental Health Act for this client group and to help draw up guidelines so that the Act is used consistently.

\section{Acknowledgements}

I wish to thank Drs Mary Lindsey, Yvonne Wiley and Peter Carpenter for help in compiling the questionnaire, and all those who completed it.

\section{References}

Gostin, L. (1983) A Practical Guide to Mental Health Law. London: Mind. Page 6.

MURPHY, E. (1990) The Mental Health Act and what is not in it. In Psychiatry and the Law (eds. Bradley, J. J. et al) Southampton: Duphar. 